\title{
Disaster Research and Social Network Analysis: Examples of the Scientific Understanding of Human Dynamics at the National Science Foundation
}

\author{
Larry Suter · Thomas Birkland · Raima Larter
}

Received: 6 February 2007/ Accepted: 21 June 2007/Published online: 8 November 2008

(C) Springer Science+Business Media B.V. 2008

How can knowledge about human behavior be accumulated effectively? How does the funding agency best assure that scientific research is effectively organized? This paper was stimulated by a meeting of nine researchers who received small grants from NSF to conduct empirical analysis of individuals affected by the hurricane disasters (Katrina and Rita) of 2005. Two of the authors are NSF program directors (one is a former director) who will discuss the philosophy and intentions of funding programs on social dynamics of disasters following the 2005 hurricanes. We discuss how NSF funding supported studies of these disasters and what was expected from the funded projects. And we will summarize the type of projects, the kinds of new scientific knowledge that has been gained, and describe what problems remain to be addressed.

\begin{abstract}
This paper was written by researchers who were program directors of the National Science Foundation during 2006. Larry Suter is currently a program director in the Division of Research, Evaluation and Communication, of the Education and Human Resources Directorate. Thomas Birkland was a program director for the Infrastucture Management and Hazards Response Program in the Division for Civil, Mechanical, and Manufacturing Innovation in the Engineering Directorate, and is now the Director of the Center for Policy Research at the University at Albany, State University of New York. Raima Larter is a Program Director in the Theoretical and Computational Chemistry Program of NSF.

Any opinions, findings, conclusions or recommendations expressed in this publication are those of the authors and do not necessarily reflect the views of the National Science Foundation.
\end{abstract}

\section{Suter $(\bowtie)$}

Division of Research, Evaluation and Communication, Education and Human Resources Directorate, The National Science Foundation, 4201 Wilson Boulevard, Arlington, VA 22230, USA e-mail: suter@nsf.gov

\section{T. Birkland}

School of Public and International Affairs, North Carolina State University, Raleigh, NC 27695, USA

\section{R. Larter}

Mathematical and Physical Sciences, The National Science Foundation, 4201 Wilson Boulevard, Arlington, VA 22230, USA 
One significant theme found in the selected social science research projects following the hurricane disasters is how social networks affected individual choices. Thus, this paper will also describe how some of the research projects funded by various programs at NSF have included studies of social networks and how that knowledge was put to use in understanding the social dimensions of the hurricane disasters in 2005 .

\section{NSF and Hazards Research}

For about three decades, the NSF has maintained a program devoted to interdisciplinary study of natural and humanly caused disasters. This program, currently located in the Division for Civil, Mechanical, and Manufacturing Innovation (CMMI) in the Directorate for Engineering, is called the Infrastructure Management and Hazard Response (IMHR) program. This program originally was motivated by the creation of the National Earthquake Hazards Reduction Program in the mid-1970s, but the IMHR program is an all hazards, multidisciplinary program, in large part because one cannot separate the social aspects of earthquakes from those of other hazards. The program has generally been quite small. Recent annual funding has ranged between about \$2.2 and \$5.0 million, with annual funding of between $\$ 2$ and $\$ 5$ million, and with projects in the last year typically ranging from $\$ 100,000$ to $\$ 250,000$. NSF does make resources available in some special cases for studies of immediate disasters. For a discussion of the issues facing research on Hazards see the recent volume on disasters by the National Research Council, Facing Hazards and Disasters: Understanding Human Dimensions (2006).

In the past two years, the Human and Social Dynamics (HSD) program has been central to quick-response field research in natural hazards. HSD was initiated in FY 2004 as a way to encourage the creation of large, broadly interdisciplinary teams of researchers to investigate phenomena that transcend traditional disciplinary boundaries. It has been very successful in pulling together researchers from a wide range of science and engineering disciplines. The program was begun in FY 2004, and FY 2005 and FY 2006 were breakout years for the program, with considerably more research being funded. Funding will continue through FY 2007 and 2008. Remarkably strong research across a number of fields and disciplines was presented at the largest HSD Principal Investigators' (PI) conference thus far, held in early September 2006. At the PI conference in 2005, a special panel on tsunami research afforded SGER-funded researchers the opportunity to share the results of their research. In many cases remarkable progress had been made in a short time.

The key long-term goals of the HSD program are to:

- Improve decision making through research that focuses on the cognitive and social processes of risk construction, communication and evaluation; the role of biases in testing; the construction of decision support systems.

- Explore causes and consequences of large-scale social transformations, including globalization, democratization, technological change, and agents of change in important social institutions and subsystems. 
- Advance understanding of human behavior and performance at individual, social, and population levels.

- Encourage researchers to "think big" about integrated research questions through grants of size and duration that allow substantial coordination across researchers, disciplines and project areas.

- Support enhancements to methods and tools, including cyberinfrastructure tools, sensors, new modes of connectivity, modeling and multi user environments.

Not all of these goals are equally relevant to every project, but the key features of interdisciplinary and transformative science are extremely important to those who do research on hazards and disasters. Disasters provide opportunities to test and question existing assumptions, particularly when those differences are grounded in disciplinary commitments or conventions. Network theory and social network analysis provides an interesting example of these disciplinary differences. In both sociology and political science (for example, Robinson 2006), it is becoming clearer that policy making and decision making are characterized less by rigid hierarchies and more by somewhat fluid networks of key participants, albeit with key nodes within the network. Indeed, it is often these nodes that stimulate the greatest interest and research insights. Unlike a sociologist, a political scientist may be as concerned with the institutional arrangements and formal legal structures in a policy domain as she would be with the structure of the network per se. In other words, policy making and governance are not strictly network or hierarchical processes. Other disciplines might have other ways of looking at networks: an engineer may be more focused on physical infrastructure networks, while a sociologist may be more concerned with the relationships between stressed or broken infrastructure and the way that networks help people cope with the loss of these "taken for granted" systems. The most successful HSD projects are those that approach a problem from within a common framework that accommodates the strengths of each discipline's approach while recognizing that these strengths come from different perspectives.

Another feature of the HSD goals is an emphasis on fundamental scientific discovery, a goal that is broadly shared throughout all programs of NSF. The most essential feature of NSF funding is that the project leads to the advancement of scientific knowledge. NSF does not fund direct service provision, policy advocacy, or, for that matter, policy design and implementation as do other federal government agencies with a specific military or domestic mission to accomplish. However, NSF is very mindful of the benefits of research to society at large. This is manifest in the requirement that every proposal contain a short statement of the intellectual merit and the broader impact of the project, and is promoted by the foundation's solicitation of highlights from funded investigators. For a discussion of the relationship between pure and applied research in modern science see Stokes, Pasteur's Quadrant (1997). Highlights are short summaries of research projects that are used both to measure and explain NSF's activities under the Government Performance and Results Act (GPRA) and to demonstrate to the public that NSF has supported research that has broad value to the advancement of science and to society at large. 


\section{NSF's Scientific Approach to Hurricane Katrina and Rita Disasters}

A key component of NSF efforts to respond to Katrina was the Small Grant for Exploratory Research (SGER) mechanism. The purpose of SGERs is to fund research at the program director's discretion that will collect "ephemeral" data that would be lost unless it were collected very soon after an event, or to support "high risk/high reward" research. The "high risk" category is generally used to fund "paradigm changing" (in the sense of Thomas Kuhn 1962) research that might be transformative; of course, more often than not, such efforts do not result in immediate paradigm shifts, but the possibility of such a result is often sufficient to justify funding.

In disaster research, particularly the HSD program, the SGER mechanism has been used under the first criterion, and about half of the research funded on Hurricanes Katrina and Rita were SGERs that allowed researchers to visit stormdamaged areas or to begin data collection efforts that could potentially lead to full proposals. Several of these projects were funded in the 2006 HSD funding cycle.

The awards made to study Hurricane Katrina ${ }^{1}$ follow a practice initiated by the HSD program in 2005 to fund field researchers in the aftermath of the 2004 Sumatra earthquake and tsunami. The HSD made 11 awards on tsunamis in 2005, including six SGERs to support data collection and preliminary research in India, Sri Lanka, Thailand, and Malaysia. These projects addressed tsunami risk, warning systems, infrastructure interdependency, local knowledge of natural tsunami precursors, and cross-cultural approaches to mass fatality incidents. Research derived from these SGER grants has begun to be published, and, in the months after the tsunami, several full proposals were funded, including projects on risk, warning, and community resilience.

The NSF responded to Hurricane Katrina and Rita by making available funding for researchers to study a wide range of physical, social, and behavioral science problems, as well as engineering ones. At last count (September 11, 2006), there were 141 awards that contained either the term "Katrina," "Rita," or both terms in the project title or abstract. Of these, 84 were Small Grants for Exploratory Research (SGERs, these grants are described below) and 57 were standard awards that, in general, are subject to external peer review. Actual funds expended were split nearly evenly between SGERs and standard awards, with \$5.4 million to SGERs and \$5.7 million to standard awards, with a total commitment from NSF of $\$ 11.1$ million on proposals that took advantage of these otherwise destructive storms as opportunities for research and understanding. The Number of SGER awards made after Hurricanes Rita and Katrina are shown in Table 1.

Not all of these projects were "triggered" or inspired by the storm events themselves. Some researchers were already investigating disaster issues before the Katrina or Rita events, but their research was made timelier by these storms. In other cases, the storms provided opportunities to add case studies or to validate

\footnotetext{
${ }^{1}$ From this point forward, we will refer to Hurricane Katrina, because this event received the vast majority of attention and research funding. In so doing, we do not mean to minimize the contribution of researchers studying Rita separately or together with Katrina.
} 
Table 1 Number of awards for research on the Katrina and Rita disasters of 2005 by NSF program areas

\begin{tabular}{lc}
\hline Program & Awards \\
\hline Human and social dynamics & 24 \\
$\quad$ Dec, risk and uncertainty (HSD) & 13 \\
$\quad$ Dynamics of human behavior (HSD) & 7 \\
$\quad$ Agents of change (HSD) & 4 \\
Special studies and analyses & 23 \\
Sociology and psychology & 19 \\
Hurricane Katrina (special competition) & 18 \\
Ecology & 7 \\
Education and human resources & 6 \\
Chemical oceanography & 5 \\
Geobiology & 5 \\
Control, networks & 4 \\
Total & 111 \\
\hline
\end{tabular}

research approaches. Regardless of the motivation, disasters like Katrina can stimulate scientific inquiry and lead to greater scientific study of all disasters as well as increased public attention, at least in the short run.

Awards for the study of the consequences of Katrina were made by many different offices within NSF that included engineering, ocean studies, chemistry, social and behavioral science, biology, physical science, and undergraduate education. We have categorized funded projects among engineering (52 projects), physical and natural science (42 projects), and social science programs (46 projects). This fairly even distribution of disciplines is a reflection of the interdisciplinary approach that the broader research community has taken in the disaster field (Table 2). This diversity of awards about a single event should lead to a small explosion of scientific information about the effect of hurricane disasters on people and on the environment. Indeed, the nature and extent of the science that will come from this community will far exceed that of any hurricane in the nation's history, and the breadth of the issues covered-ranging from change in coastal resources to policy questions about mitigation to fundamental questions about the spatial distribution of racial groups, wealth, and income-will set a standard for future disaster research that will not soon be equaled.

Other NSF-funded efforts have supported quick-response disaster research. The two most important are the Earthquake Engineering Research Institute's (EERI)

Table 2 Number and amount of Katrina and Rita Awards by field of study

\begin{tabular}{lcr}
\hline Field of study & $\begin{array}{l}\text { Number } \\
\text { of awards }\end{array}$ & $\begin{array}{l}\text { Total amount } \\
\text { of awards }\end{array}$ \\
\hline Engineering & 52 & $\$ 3,106,860$ \\
Physical science & 42 & $4,015,824$ \\
Social science and education & 46 & $3,673,899$ \\
Total & 140 & $\$ 10,796,583$ \\
\hline
\end{tabular}


Learning from Earthquakes Program, and "quick response" studies program at the Natural Hazards Research and Applications Research Center at the University of Colorado, which sponsors small $(\$ 3,000)$ studies of disasters. And the NSF, along with the United States Geological Survey, the Federal Emergency Management Agency, and the National Institute of Standards and Technology, has created "The Plan to Coordinate NEHRP Post-Earthquake Investigations" (http://www.nehrp. gov/). In all these cases, the goal of funding research is to promote the testing of hypotheses and the advancement of knowledge while supporting national and international efforts to reduce the human and economic toll of disasters. The NSF's efforts in Hurricane Katrina seek to apply similar experiences to natural disasters.

\section{What Related Research Has Been Conducted on Social Networks at NSF?}

Of the small grants given to social scientists for the Katrina disaster studies, nearly half of them were concerned with some form of social network analysis and how the networks affected decisions to leave during the storm, how they assisted or not persons after the storm, and how the changes in the environment affected social networks. Thus, social scientists previously grounded in many aspects of psychology, sociology, political science, and economics independently noticed that the human response to this major disaster was likely to be shaped by pre-existing or new social networks. The articles in this journal issue reflect the variety of methods and uses of network analysis that were found to be suitable for study.

Studies of social networks have been supported by NSF for many years. However, the recent growth in attention to networks might be explained by the growing ability to conduct the types of analysis necessary. Figure 1 shows the growth in awards for social network analysis throughout NSF for the past 16 years. Clearly, the growth in NSF support for this type of research really took off in 2003, driven largely by the growing adoption of Social Network Analysis across many disciplines.

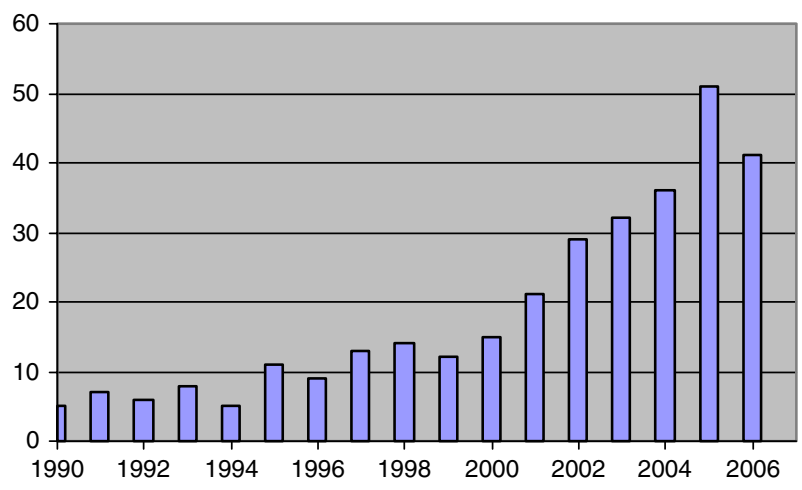

Fig. 1 Number of Social Network Awards by NSF: 1990-2000 


\section{Cross Discipline Examples}

While many program areas are involved with making awards about the disaster to researchers, this variety does not necessarily lead to researchers from one discipline working with researchers in another discipline. The NSF, and particularly the Human and Social Dynamics Program, is committed to interdisciplinary research that seeks to pose and address questions that cannot be addressed through one disciplinary approach. For example, a considerable amount of interest in evacuation and warning has resulted from the perception that evacuation failed in New Orleans in Hurricane Katrina. The evacuation problem is neither an engineering problem nor a socio-behavioral problem - it is both, and both disciplines need to understand how engineered systems interact with human behaviors. Some projects have been able to integrate methods of research from each field.

It is important to note that there is a difference between interdisciplinary research and multidisciplinary research. Projects that rely on investigators from multiple disciplines but that fail to integrate the contributions and perspectives of each discipline are multidisciplinary but not interdisciplinary. For reasons relating to the organization of academic departments at universities, language for communication, and the reward structure in many disciplines, interdisciplinary research is more difficult to foster, and it often fails to find champions within the disciplines. Recent experiences suggest that interdisciplinary research is not only possible, but is one of the most promising ways to address difficult problems (Derry et al. 2006).

\section{Methods of Research Employed by the Katrina SNA Projects?}

Because these projects are interdisciplinary, the research techniques must be interdisciplinary as well. Some of the projects used survey methods to identify social networks. An example might be asking the survey respondent who they had received information about the storm events from. Other studies conducted long interviews with respondents, like high school students, who were moved to other cities outside of New Orleans. An innovative approach by Nash Contractor used the World Wide Web to find linkages between organizations that posted situation reports as they participated in the recovery process in the flooded area.

\section{Contributions of Science Disciplines to Network Analysis}

Recent advances in the theory of networks coupled with increased computational power and resources have now made it possible to begin to investigate ways in which the results of NSF investments can be tracked and mapped onto the changing landscape of science. In the past it was not easy, or sometimes even possible, to ask whether the investments of research dollars were correlated with the growth of new areas of science, so determining where to make the best investments involved a great deal of guesswork. Now, with the availability of searchable databases of scientific literature and citation patterns, and the advent of new scientometric tools, 
it is possible to analyze the growth and development of new areas of science. These tools rely on a theory of "the system" as a complex interacting network of scientific investigators bound together by common interests, collaborations, and shared communication. Developments in the theory of such a complex system might, in the future, even make it possible to use forecasting techniques to predict the results which NSF investments might have on the evolution of science.

Networks are important in many areas of science, but still poorly understood. The heavily regulated and feedback-dominated networks of chemical reactions which comprise a living cell, for example, are crucial to the molecular basis of life. At the other extreme, networks of individuals in a social system interact by rules and through processes that are equally poorly understood. Nevertheless, recent results from theoretical studies of networks have revealed structural and dynamic similarities between social networks and the chemical networks that characterize living systems. An interesting and timely question is: are there, overarching principles of networks that apply at both the molecular level and at the human level? Can research into one of these areas of investigation advance our understanding of the other?

Groups of individuals, organizations, and even nations evolve and change in ways that are not easily understood, and even less easily modeled. A meeting of principal investigators from the first round of HSD awards was held in September 2005, and part of the discussion centered on the need for better theoretical methods and computational techniques for modeling these most complex systems. A follow-up workshop was held in October 2006, and brought together researchers from the physical sciences and engineering with social and behavioral scientists. Among the techniques discussed were: agent based modeling methods; social network theory; and complex systems theory, all techniques which have been brought to bear on human and social systems, sometimes with more or less encouraging results. The kind of dynamic network modeling needed for the description of human systems might be similar to that needed in modeling biological systems at the cellular or tissue level, or chemically reacting systems in materials science. In turn, the theoretical study of social networks might also reveal theoretical principles that will help elucidate complex functioning of molecular networks in biological systems.

While physical scientists have a great deal to contribute to these important areas of investigation in the social sciences, advances in the study of social systems will help advance physical science as well. The ability of societies to respond to disasters is heavily dependent on our understanding of the dynamics of social networks, which may be in place before the disaster, or which may actually arise as a result of the disaster. Being able to predict when a communication network may fail, or what network structures will be more flexible and adaptable to changing circumstances, are outcomes we might expect from a better theoretical understanding of these complex networks. Even closer to home, being able to predict how the complex interacting network of individuals who comprise our principle investigator community reacts to investments of funding could be very useful and might reveal interesting new areas for investment that we might not otherwise have noticed. 


\section{What Research Questions About Social Networks Could be Addressed in the Future?}

The demands of dealing with large social problems such as predicting how the population affected by a disaster would respond to massive flooding can stimulate the generation of new social theory and methods. The Katrina disaster of 2005 was such an event and it stimulated funding agencies to create new approaches to encourage the scientific study of population response. NSF funding produced several new research projects about social networks that provide new information about social responses to that disaster and they demand new social theory to explain human dynamics.

Human behavior is complex because of the interaction of competing demands on individuals as they are confronted with choices to move or remain in the face of wind and water. Katrina was especially complex as a disaster because the public information available to residents of New Orleans and Southern Mississippi prior to the landing of a large storm did not necessarily anticipate the secondary effects of flooding from water sources in the area. Yes, some information was known by leaders, but in the hours of the storm, this information was not immediately discussed or disseminated.

What lessons for social research methods and theory are useful to those who plan future surveys and analysis of social practice? The lessons to public policy may also be of concern to the participants in these studies, but those lessons will be better served by reliable scientific information about the behavior of individuals and groups engaged in the live events of the largest and most damaging storm in America's history. Could enduring social theory result from this event? The Katrina grants discussed in this issue provide insights in spite of having been conducted in less than perfect conditions for funding and engagement with the community.

Some of the enduring sociological issues that can be addressed by the data available from this study or studies are these:

- The availability of new mathematical models and high speed computing affect the description and explanation of relevant social systems. For example, Contractor shows that information provided by public resource agencies during the disaster can be described in a system of social networks in which the organizations respond to each other.

- The number of persons affected by the Katrina disaster was very large. About 2 million persons were affected. The studies supported by NSF indicated that those represented in both local and displaced-persons surveys were more likely to be black, old, unmarried women. Do these survey responses provide important insights for future planning?

- Many projects assume that an individual's tie to a network is an independent factor for predicting post Katrina adjustment. Did the empirical data derived from the study support that notion? Does an increase in social contact possibilities (such as church membership) assist adjustment after the storm? 
Some of the questions that arise during data collection and analysis of social networks are methodological and organizational. Future researchers need to consider the following issues:

1. Develop agreed upon measurement methods of social networks and share those methods with others;

2. Interdisciplinary research: Connect learning from computer science to sociology; Relate the results of cross sectional with longitudinal studies;

3. Develop experiential theory of how social networks affect decision making following unexpected disasters;

4. Develop theory of how other decisions affect social networks;

5. Exchange theory and data with researchers in other countries.

\section{References}

Committee on Disaster Research in the Social Sciences. (2006). Facing hazards and disasters: Understanding human dimensions. Washington, DC: National Research Council.

Derry, S. J., Schunn, C. D., \& Gernsbacher, M. A. (Eds.). (2005). Interdisciplinary collaboration: An emerging cognitive science. New Jersey: Lawrence Erlbaum Associates.

Kuhn, T. (1962). The structure of scientific revolutions. Chicago: University of Chicago Press.

Robinson, S. E. (2006). A decade of treating networks seriously. Policy Studies Journal, 34(4), 589-598.

Stokes, D. E. (1997). Pasteur's quadrant: Basic science and technological innovation. Washington, DC: Brookings Institution Press.

The plan to coordinate NEHRP post-earthquake investigations (http://www.nehrp.gov/). 